\title{
SEKSISME DALAM SAINS
}

\author{
Nadiatus Salama \\ Fakultas Dakwah dan Komunikasi \\ IAIN Walisongo Semarang
}

\begin{abstract}
Abstrak
Seksisme telah terjadi sejak lama yang dilakukan oleh kelompok yang tidak mengakui kesetaraan jender. Meskipun diskriminasi ini merupakan hal yang buruk dan berlawanan dengan hukum, namun perilaku ini masih eksis, dan mendarah daging dalam pemikiran, sikap dan tindakan sebagian masyarakat yang sudah modern ini. Sejumlah sains dan riset turut digunakan untuk membenarkan sejumlah keyakinan yang seksisme, padahal, telah terjadi bias dan mis-interpretasi dalam riset tersebut. Perempuan dilihat sebagai suatu sosok yang menjadi masalah oleh sains. Itulah sebabnya, saat ini, perempuan bersuara lebih keras dalam memperjuangkan hakhaknya daripada pada masa sebelumnya, berharap agar segera dihentikan dan tidak berlarut-larut. Melawan seksisme bisa dilakukan secara individu maupun kolektif, dengan cara melaporkan diskriminasi yang terjadi, atau juga memberikan penyuluhan atau pendidikan tentang seksisme agar diskriminasi ini tidak menjadi lebih parah lagi. Di sisi lain, negara, sebagai institusi resmi pelindung warganya, juga wajib menjadi pengayom dan pembela korban seksisme.
\end{abstract}

Kata Kunci: seksisme, sains, diskriminasi, perempuan, laki-laki

\section{A. Seksisme}

Menurut Peter Sterns, dulu, dalam masyarakat pra-agrikultur (sebelum tahun 1750), perempuan memegang posisi yang setara dengan laki-laki. Namun, itu kemudian berubah ketika telah terjadi adopsi pertanian yang menetap, dan kemudian budaya laki-laki mulai melembagakan konsep bahwa perempuan lebih rendah daripada laki-laki ${ }^{1}$ Contoh yang nyata

${ }^{1}$ Peter N. Stearns (Narrator), A Brief History of the World Course No. 8080 [Audio CD]. The Teaching Company. 
tentang seksisme dalam masyarakat kuno adalah adanya hukum tertulis yang mencegah perempuan berpartisipasi dalam proses politik (misalnya: wanita Romawi tidak boleh mengikuti Pemilu atau memegang jabatan politik). ${ }^{2}$

Istilah seksisme dikenal secara luas saat terjadi Gerakan Pembebasan Perempuan (Women's Liberation Movement) pada tahun 1960. Ketika itu, para penganut teori feminis menyebutkan bahwa tekanan terhadap perempuan telah menyebar dan terjadi di hampir seluruh lapisan masyarakat, sehingga mereka mulai bersuara lebih lantang tentang paham seksisme daripada paham male chauvinism ${ }^{3}$. Pembela paham male chauvinists biasanya adalah lakilaki yang meyakini bahwa mereka lebih hebat daripada perempuan. Paham seksisme merujuk pada perilaku kolektif yang merefleksikan masyarakat sebagai suatu keseluruhan.

Seksisme (sexism) merupakan suatu bentuk prasangka ${ }^{4}$ atau diskriminasi kepada kelompok lain hanya karena perbedaan jender atau jenis kelamin. ${ }^{5}$ Dalam hal ini, biasanya wanita cenderung dianggap lemah. Tindakan seksisme, kemungkinan, bisa bersumber dari stereotipe ${ }^{6}$ terhadap peran jender ${ }^{7}$ dan keyakinan bahwa pada jenis kelamin tertentu memiliki posisi yang lebih baik dan superior dibanding yang lainnya. ${ }^{8}$ Seksisme bisa merujuk pada seseorang yang melakukan diskriminasi, baik yang diekspresikan melalui tindakan, perkataan, maupun hanya berbentuk suatu keyakinan/ kepercayaan. Seksisme terkadang bisa juga terjadi tanpa disadari oleh si pelaku, baik disengaja maupun tidak disengaja, seperti yang pernah di-

\footnotetext{
2 Bruce W. Frier and Thomas A.J. McGinn, A Casebook on Roman Family Law (Oxford University Press: American Philological Association, 2004), pp. 31-32, 457, et passim.

${ }^{3}$ Rasa cinta dan bangga yang berlebihan sebagai sosok maskulin serta mengagungagungkan jender laki-laki.

${ }^{4}$ Prasangka atau prejudice: sikap negatif suatu kelompok dan atau individu terhadap seseorang yang disebabkan oleh keanggotaan orang tersebut dalam kelompok tertentu.

${ }^{5} \mathrm{http}: / /$ www.merriam-webster.com/dictionary/sexism.

${ }^{6}$ Stereotipe adalah kepercayaan tentang atribut pribadi sekelompok orang yang terkadang dibesar-besarkan, tidak akurat, atau berupa perlawanan terhadap ide-ide baru. Faham ini cenderung mengasosiasikan sekelompok orang dengan ciri-ciri/sifat tertentu.

${ }^{7}$ Nakdimen KA, The American Journal of Psychiatry, 1984, 141 (4), pp. 499-503.

${ }^{8}$ Doob, Christopher B., Social Inequality and Social Stratification in US Society, Upper Saddle River, (NJ: Pearson Education, Inc., 2013).
} 
laporkan oleh The Smithsonian American Art Museum. Pada tahun 2011, lembaga tersebut pernah melakukan survei tentang karya seni di Amerika yang menunjukkan bahwa terdapat 5.193 patung di ruang publik, di mana sejumlah 394 dari patung yang ada menunjukkan jender perempuan. ${ }^{9}$

Seksisme, meskipun berbentuk kebencian terhadap orang lain yang bergantung pada perbedaan jenis kelamin, tetapi dapat juga merujuk pada semua sistem diferensiasi pada seks individu. Seksisme dapat diwujudkan dengan berbagai kepercayaan atau sikap, seperti:

1. Kepercayaan bahwa satu jenis kelamin/gender lebih berharga dari yang lain.

2. Chauvinisme pria atau wanita.

3. Sifat misogini (kebencian terhadap wanita) atau misandria (kebencian terhadap laki-laki).

4. Ketidakpercayaan kepada orang yang memiliki jenis jender yang berbeda.

Seksisme yang ambivalen mencerminkan seksisme jahat (yang diwarnai perasaan negatif dan kekecewaan terhadap perempuan) maupun seksisme baik (yang diwarnai afeksi, rasa hormat, dan kagum) secara bersamaan. Orang-orang yang berasal dari masyarakat yang tidak mengakui kesetaraan laki-laki dan perempuan dalam bidang sosial, ekonomi dan politik, cenderung untuk memperlihatkan seksisme ambivalen yang tinggi

Meskipun diskriminasi berdasarkan jenis kelamin merupakan hal yang buruk dan berlawanan dengan hukum, namun perilaku seperti ini masih eksis dan bertahan dalam lingkungan masyarakat yang modern saat ini, bahkan di negara-negara maju sekalipun (seperti Inggris dan Amerika). Paham ini masih mendarah daging dalam pemikiran, tindakan, dan sikap mereka. Hal ini, dapat juga terjadi dalam lingkungan kerja. Pegawai perempuan bisa mengalami diskriminasi dalam hal pemberian tugas kerja, pemberian gaji, atau promosi jabatan. ${ }^{10}$ Pelaku seksisme yang ekstrim

\footnotetext{
${ }^{9}$ Harper's Index. Harper's (Harper's Foundation), 17 July, 2011.

${ }_{10}$ Macionis, Gerber, John, Linda, Sociology, 7th Canadian Ed. Toronto, (Ontario: Pearson Canada Inc., 2010), p. 298.
} 
bahkan bisa saja melakukan kekerasan seksual, pemerkosaan, dan berbagai bentuk pelecehan seksual lainnya. ${ }^{11}$

\section{B. Legitimasi Seksisme ...?}

Sains atau ilmu pengetahuan juga turut digunakan untuk membenarkan sejumlah keyakinan yang seksisme. Ada kepercayaan yang berlaku dalam ilmu pengetahuan pada abad ke-19 bahwa perempuan lebih rendah dari laki-laki. Sebagai contoh, Charles Darwin pernah mengungkapkan bahwa laki-laki memiliki kemampuan yang lebih baik/tinggi daripada perempuan dalam berbagai hal yang dilakukannya, baik yang terkait dengan aktivitas yang hanya menggunakan panca indera atau tangan maupun aktivitas yang membutuhkan pemikiran/analisis mendalam, argumentasi, dan imajinasi. ${ }^{12}$

Salah satu 'temuan' pada era itu juga berasal dari perintis fisiologis psikolog Broca, yang mempelajari volume relatif otak manusia. Dia menyimpulkan bahwa rata-rata perempuan memiliki otak yang lebih kecil dibandingkan laki-laki. Ini berarti bahwa perempuan kurang cerdas daripada laki-laki. Gould juga menunjukkan, bagaimanapun, rerata tidak disesuaikan untuk memperhitungkan tinggi badan (orang yang lebih tinggi memiliki otak yang lebih besar), atau usia (orang yang tua bisa saja mengalami pengurangan volume otak). ${ }^{13}$ Kebetulan, sejumlah perempuan yang dijadikan sampel penelitian oleh Broca adalah perempuan yang tidak tinggi dan lebih tua usianya dibandingkan yang sampel laki-laki. Padahal, faktor-faktor inilah yang digunakan oleh Broca untuk menjelaskan perbedaan ukuran volume otak.

Saat itu, proporsi laki-laki ditempatkan dalam berbagai lini secara superior dan strategis karena laki-laki yang berbakat dan memiliki kemampuan jumlahnya lebih banyak daripada perempuan. Demikian pula, dalam

${ }^{11}$ Gerald D. Robin, Forcible Rape Institutionalized Sexism in the Criminal Justice System, Division of Criminal Justice, University of New Haven, t.t., th.

${ }^{12}$ Shields, S. (1978). "Sex and the Biased Scientist", New Scientist 7 December, p. 752-4.

${ }^{13}$ Gould, S.J. (1978). “Women's Brains”, New Scientist 2 November, 364-6. 
kajian ilmu psikologi. Perempuan sulit mendapat pengakuan dalam psikologi. Isi materi dalam studi psikologi sebagian besar lebih peduli dengan perilaku dan pengalaman hidup laki-laki. Kajian psikologi telah menciptakan sejumlah hambatan untuk menerima dan mengembangkan peran perempuan. Cattell, yang menerbitkan edisi pertama dari American Men of Science pada tahun 1906, menyatakan bahwa ilmu psikologi merupakan ilmu yang sangat baru, yang memiliki 186 psikolog, namun hanya memiliki 22 psikolog perempuan. Meski demikian, pencapaian ini sudah merupakan hal yang luar biasa karena hingga pada pergantian abad ke-20, sebagian besar universitas yang besar dan terkenal di Amerika tidak mengizinkan perempuan untuk mengambil gelar sarjana di bidang psikologi.

Furumoto dan Scarborough juga membandingkan karir psikolog perempuan ini dengan rekan-rekan laki-laki mereka dan menyatakan bahwa kecil kemungkinannya bagi mereka untuk bisa meraih status profesional yang sama dengan kaum laki-laki. Mereka mencatat bahwa sejumlah faktor tertentu yang terkait dengan jender turut memengaruhi kesuksesan para psikolog perempuan ini, antara lain, yaitu: (1) mereka tidak diikutsertakan dalam posisi tertentu karena mereka adalah perempuan, (2) perempuan memiliki tanggung jawab terhadap anggota keluarga mereka, dan (3) perempuan menghadapi dilema antara mengutamakan keluarga atau mengembangkan karir $^{14}$

Kajian dalam ilmu psikologi klasik juga telah menyiratkan pelecehan terhadap kaum perempuan. Berikut ini kutipan dari para psikolog laki-laki:

Kita harus mulai menyadari bahwa meski banyak perempuan yang ingin menjadi insinyur atau ilmuwan yang baik, mereka tetaplah seorang ibu dan teman perempuan dari kaum laki-laki. (Bruno Bettelheim, 1965, dikutip dalam Weisstein, 1992, hlm. 61). ${ }^{15}$

${ }^{14}$ Furumoto, L. \& Scarborough, E., Placing women in the history of psychology: the first American women psychologists, in J.S. Bohan (ed.), Seldom Seen, Rarely Heard: Women's Place in Psychology, (Boulder, CO: Westview, 1992), pp. 337-53.

${ }^{15}$ Weisstein, N., Psychology constructs the female, or the fantasy life of the male psychologist (with some attention to the fantasies of his friends the male biologist and the 
Identitas perempuan didefinisikan karena daya tarik dan keselektivannya dalam memilih laki-laki yang ingin ia cari... (Erik Erikson, 1964, dikutip dalam Weisstein, 1992, hlm. 62). ${ }^{16}$

Anda (maksudnya adalah untuk perempuan) adalah masalah bagi Anda sendiri. (Sigmund Freud, 1973. Pernyataan ini diterbitkan dan dibukukan pertama kali pada tahun 1933$)^{17}$

Pernyataan-pernyataan di atas menunjukkan pandangan yang "sangat laki-laki" terhadap perempuan. Banyak pria yang memiliki pandangan serupa. Namun, masyarakat awam perlu membedakan apakah itu termasuk pandangan pribadi atau pandangan akademik yang ilmiah. Bisa jadi, pandangan-pandangan miring ini hanya pendapat subjektif yang sinis terhadap eksistensi perempuan. Atau bahkan ada pula pendapat yang lebih mengganggu seperti yang dikutip dari psikiater Antony Storr, di bawah ini:

Keinginan untuk disandera oleh seorang laki-laki yang kejam guna melampiaskan hasrat seksualnya merupakan keinginan yang universal dari kaum perempuan. (Storr, 1968). ${ }^{18}$

Kutipan di atas hanya salah satu pilihan dari banyaknya ungkapan buruk tentang perempuan. Pernyataan bahwa perempuan ingin menjadi "korban" kekerasan laki-laki tampak menyeramkan, jika memang dilegitimasi oleh ilmu psikologi dengan cara ini. Perempuan dilihat sebagai suatu sosok yang menjadi masalah oleh ilmu psikologi, maupun hanya sebagai pengasuh anak-anak, dan pelayan bagi laki-laki. Itulah sebabnya, saat ini, perempuan lebih keras dalam menyuarakan hak-haknya dibandingkan pada masa sebelumnya.

Perlu dicatat bahwa banyak studi klasik dalam ilmu psikologi yang sebagian besar dilakukan pada subjek laki-laki, misalnya, dua kajian yang

male anthropologist), in J.S. Bohan (ed.), Seldom Seen, Rarely Heard: Women's Place in Psychology, (Boulder, CO: Westview, 1992), pp. 61-78.

${ }^{16} \mathrm{Ibid}$.

17 Freud, S., The New Introductory Lectures on Psychoanalysis, (Harmondsworth: Penguin, 1973), p. 146.

${ }^{18}$ Storr, A. Human Aggression, (Harmondsworth: Penguin, 1968), p. 91. 
paling sering dijadikan bahan rujukan tentang prasangka, yaitu studi yang dilakukan oleh Sherif tentang konflik dan kompetisi pada tahun $1956^{19}$, dan Tajfel pada tahun $1970^{20}$ yang meneliti dua kelompok anak laki-laki. Kitzinger juga menunjukkan bahwa model identitas Erikson tentang seluruh rentang kehidupan didasarkan pada wawancara dengan laki-laki ${ }^{21}$, dan teori Kohlberg tentang perkembangan moral didasarkan pada serangkaian penelitian serta wawancara dengan laki-laki. ${ }^{22}$

Seksisme banyak dijumpai dalam berbagai riset. Seperti penelitian yang dilakukan oleh psikolog Carol Tavris. Hasil penelitiannya -entah ini objektif atau tidak, kadang turut mengundang tanda tanya tentang keabsahan suatu hasil penelitian- mencatat bahwa kesimpulan yang dibuatnya telah diambil dari penelitian tentang perbedaan jenis kelamin, yang menyimpulkan bahwa: (1) perempuan memiliki harga diri yang lebih rendah dibandingkan laki-laki, (2) perempuan tidak menghargai usaha yang telah mereka lakukan meskipun mereka melakukan pekerjaan yang sama jenis dan bobotnya, tidak seperti laki-laki yang cenderung menganggap hasil karyanya bagus, (3) perempuan cenderung untuk mengatakan bahwa mereka terluka (atau menjadi korban) daripada menyatakan bahwa mereka marah (atau menjadi pelaku kejahatan), serta (4) perempuan mengalami kesulitan yang lebih dari kaum laki-laki dalam mengembangkan rasa terpisah dari diri sendiri. ${ }^{23}$

Meski sejumlah pernyataan di atas bisa benar atau salah, namun penulis cenderung untuk menyatakan bahwa ada bias dan mis-interpretasi dalam riset tersebut meskipun Tavris juga membuat pembelaan bahwa bias ini biasanya menggambarkan masalah-masalah yang dirasakan perempuan 96-102.

${ }^{19}$ Sherif, M., Experiments in group conflict, Scientific American 195, (1956), pp. 54-8.

${ }^{20}$ Tajfel, H. Experiments in intergroup discrimination, Scientific American 223, (1970),

${ }^{21}$ Kitzinger, C., "Challenging Gender Biases: Feminist Psychology at Work", Psychology Review 4., 1998, pp. 18-20.

${ }^{22}$ Kohlberg, L. "The Child as a Moral Philosopher: Psychology Today", in D. Krebs (ed.), Readings in Social Psychology, 2nd edn, London: Harper Collins, 1968.

${ }^{23}$ Tavris, C., The mismeasure of woman: paradoxes and perspectives in the study of gender, in J.D. Goodchilds (ed.), Psychological Perspectives on Human Diversity in America, (Washington, DC: American Psychological Association, 1991), pp. 87-135. 
daripada masalah yang dirasakan laki-laki. Studi empiris telah menemukan keyakinan budaya dalam masyarakat luas bahwa laki-laki lebih dihargai secara sosial dan dianggap lebih kompeten daripada perempuan dalam sejumlah kegiatan, ${ }^{24}$ misalnya, Susan Fiske, dkk. melakukan survei kepada sembilan sampel yang beragam dari berbagai daerah di Amerika Serikat. Fiske dkk. menemukan bahwa anggota dari sampel, tanpa memandang usia, yang berkategori "laki-laki" lebih tinggi dari kategori "perempuan" pada berbagai skala multidimensi kompetensi. ${ }^{25}$

Seksisme dan stereotipe bisa terjadi juga dalam kajian ilmu yang lain, seperti pada ilmu matematika yang pernah dilakukan oleh Margaret dkk. Hasil riset mereka menunjukkan bahwa kemampuan kinerja perempuan pada tes matematika dan keterampilan kuantitatif lebih rendah dibandingkan dengan laki-laki. ${ }^{26}$ Suatu penelitian juga menemukan bahwa laki-laki menilai kemampuan menyelesaikan tugas mereka lebih tinggi/baik daripada perempuan pada level/tingkat kesulitan yang sama. Hal ini bisa menjadi "bias penilaian diri" terhadap perempuan dan memperkokoh seksisme.

\section{Perlu Antitesis Seksisme}

Terkadang, sejumlah orang membuat bahan cerita lucu atau bercanda tentang seorang individu dari jender yang berbeda karena, mungkin, mereka tidak memiliki rasa empati pada lawan jenis. Yang tanpa disadari, hal itu bisa menjadi sesuatu yang menyakitkan bagi orang lain. Kata-kata sinis yang melecehkan yang mengingatkan bahwa seksisme adalah hal yang tidak bisa ditoleransi. Tidak cukup hanya menggertak seseorang yang membuat candaan seksisme. Masyarakat luas perlu melawan seksisme dan memberikan dukungan bagi para korban seksisme.

\footnotetext{
${ }^{24}$ Wagner, David G. and Joseph Berger, Gender and Interpersonal Task Behaviors: Status Expectation Accounts. Sociological Perspectives, Vol. 40, No. 1, 1997, pp. 1-32.

${ }^{25}$ Fiske, Susan T., Amy J. C. Cuddy, Peter Glick, Jun Xu, A Model of (Often Mixed) Stereotype Content: Competence and Warmth Respectively Follow From Perceived Status and Competition. Journal of Personality and Social Psychology, Vol. 82, No. 6, 2002, p. 892.

${ }^{26}$ Shih, Margaret, Todd L. Pittinsky and Nalini Ambady, Stereotype Susceptibility: Identity, Salience and Shifts in Quantitative Performance. Psychological Science, Vol. 10, No. 1, 1999, pp. 80-3.
} 
Para kaum perempuan perlu menyadari bahwa ucapan/tindakan seksisme kadang sudah di luar batas dan hal ini harus segera dihentikan agar tidak berlarut-larut. Kaum hawa perlu memahami bahwa seksisme adalah ilegal dan mereka harus memperjuangkan hak dan harga diri mereka. Hal ini perlu dilakukan mengingat: (1) kaum perempuan adalah manusia yang berharga dan memiliki hak untuk diperlakukan setara dengan kaum lakilaki, dan (2) perempuan bisa menjadi pelaku/agen perubahan sosial untuk memperbaiki situasi feminis psikologi. ${ }^{27}$

Di sisi lain, ketika ilmu psikologi yang diharapkan sebagai sarana perubahan sosial ternyata bisa bertentangan dengan keilmuan akademik yang ilmiah, artinya bahwa psikologi yang seharusnya objektif dan terpisah dari kontroversi yang tidak berujung, namun realitanya, psikologi justru telah ikut aktif dan terlibat dalam "perang" dan propaganda, sehingga menjadi mustahil untuk menyatakan bahwa ilmu psikologi berdiri di luar perdebatan masalah perubahan sosial dan politik.

Dewasa ini, banyak cara yang bisa dilakukan untuk melawan paham seksisme ini. Melawan seksisme bisa dilakukan secara individu maupun kolektif, dengan cara melaporkan diskriminasi yang terjadi, atau juga memberikan penyuluhan atau pendidikan tentang seksisme. Jika seseorang pernah melihat diskriminasi seks atau mengalami sendiri, pastikan bahwa ada orang lain yang tahu kejadian tersebut. Hal ini bisa mencegah praktik diskriminasi agar tidak menjadi lebih parah lagi.

Negara, sebagai institusi resmi pelindung warganya juga wajib menjadi pengayom. Hal ini tertuang dalam Perjanjian Hukum untuk Diskriminasi Seks yang lahir sejak tahun 1975 yang menyatakan bahwa:

"Negara melindungi setiap individu dari tindakan atau praktik diskriminatif dalam dunia kerja, pelatihan, pendidikan, penyediaan dan penjualan barang, fasilitas dan jasa, gedung dan pelaksanaan fungsifungsi publik berdasarkan jenis kelamin."

Seksisme juga bisa terjadi dalam dunia kerja, termasuk di dalamnya meliputi diskriminasi dalam pemberian jumlah gaji. Namun, adanya The

${ }^{27}$ Kitzinger, C. loc.cit. 
Equal Pay Act pada tahun 1970 merupakan mandat tentang persamaan hak dalam perolehan gaji. Jika ada yang melanggar hukum ini maka pengadilan adalah jalan satu-satunya lembaga yang tepat untuk melaporkan tindakan seksisme. Perjuangan melawan seksisme terjadi di hampir semua negara di dunia. Pelaporan seksisme kepada institusi yang menangani/memperjuangkan persamaan hak juga dapat membantu memberantas perilaku tersebut. The Equality and Human Rights Commission (Organisasi Kesetaraan dan Komisi Hak Asasi Manusia) dan the Women and Equality Unit (Perempuan dan Unit Kesetaraan) merupakan organisasi yang berjuang untuk kesetaraan dan melawan seksisme di Negara Inggris. Pada tahun 2008, organisasi yang menangani kerja sama ekonomi dan pembangunan (Organisation for Economic Co-operation and Development/OECD) menemukan fakta bahwa jumlah pegawai perempuan makin meningkat namun telah terjadi kesenjangan gaji di hampir semua tempat kerja. Rata-rata jumlah gaji pegawai perempuan berjumlah $17 \%$ lebih rendah daripada pegawai laki-laki dan sejumlah $20 \%$ perempuan juga memiliki kesempatan kerja yang lebih rendah dibandingkan laki-laki. ${ }^{28}$ Negara-negara yang menjadi anggota OECD, termasuk Amerika Serikat, ${ }^{29}$ meskipun telah memiliki UndangUndang anti diskriminasi, namun peraturan ini masih sulit digunakan untuk menjadi "alat penekan." 30

Meski demikian, makin lama dan berangsur-angsur, kesadaran untuk melakukan antithesis terhadap seksisme mulai menampakkan hasilnya, seperti yang terjadi di Ekuador. Sekumpulan anak muda mendirikan The Pink Helmets (Cascos Rosas), pada Mei 2011, untuk menyatukan para remaja dalam memerangi machismo. ${ }^{31}$ The Pink Helmets menerbitkan buku panduan yang berisi petunjuk dan saran tentang bagaimana mengakhiri kekerasan yang terjadi dalam keluarga, pertemanan, dan masyarakat. Kelompok ini

\footnotetext{
${ }^{28}$ OECD Employment Outlook - 2008 Edition Summary in English. OECD, Paris, 2008, p. 3-4.

29 The U.S. Equal Employment Opportunity Commission. "Facts About Compensation Discrimination". Retrieved 2008-04-23.

30 OECD. OECD Employment Outlook - 2008 Edition Summary in English. OECD, Paris, 2008, p. 3-4.

${ }^{31}$ Hollows, Joanne (2000). Feminism, Femininity and Popular Culture. Manchester, UK: Manchester University Press. p. 139. ISBN 0-7190-4394-8. Retrieved March 11, 2013.
} 
menyebut diri mereka sebagai neomasculinos. Kelompok yang terdiri dari para remaja yang berusia 15-20 tahun ini menggandeng UN Women (bagian dari the United Nations/Persatuan Bangsa-Bangsa) dalam mengunjungi sekolah-sekolah untuk memberikan ceramah dan pencerahan guna membuat gerakan melawan chauvinisme dan kekerasan yang kerap terjadi di negara tersebut. Gerakan ini bertujuan untuk meningkatkan kesetaraan jender serta mengakhiri kekerasan dan seksisme terhadap perempuan yang lazim terjadi dalam budaya mereka.

Terlepas dari perbedaan dalam memandang seksisme, satu solusi yang dapat menyelesaikan kedua persoalan itu adalah perlunya mengubah cara pandang, sikap, dan perilaku, agar hati dan pikiran juga ikut menghilangkan seksisme. Perlawanan terhadap seksisme perlu dilakukan agar praktik diskriminasi ini tidak menjadi lebih parah lagi di masa yang akan datang.[]

\section{Daftar Pustaka}

Bruce W. Frier and Thomas A.J. McGinn, A Casebook on Roman Family Law, Oxford University Press: American Philological Association, 2004.

Doob, Christopher B., Social Inequality and Social Stratification in US Society. Upper Saddle River, NJ: Pearson Education, Inc., 2013.

Fiske, Susan T., Amy J. C. Cuddy, Peter Glick, Jun Xu A Model of (Often Mixed) Stereotype Content: Competence and Warmth Respectively Follow From Perceived Status and Competition. Journal of Personality and Social Psychology, 82, 6, 892, 2002.

Freud, S., The New Introductory Lectures on Psychoanalysis, Harmondsworth: Penguin, 1973.

Furumoto, L. \& Scarborough, E. Placing women in the history of psychology: the first American women psychologists, in J.S. Bohan (ed.), Seldom Seen, Rarely Heard: Women's Place in Psychology, Boulder, CO: Westview, 1992.

Gerald D. Robin, Forcible Rape Institutionalized Sexism in the Criminal Justice System, Division of Criminal Justice, University of New Haven, t.th.

Gould, S.J., "Women's brains", New Scientist 2 November, 1978, pp. 364-6.

Harper's Index. Harper's, Harper's Foundation,1934, 17. July, 2011. 
Hollows, J., Feminism, Femininity and Popular Culture, Manchester, UK: Manchester University Press, 2000.

http://www.merriam-webster.com/dictionary/sexism.

Kitzinger, C., "Challenging gender biases: feminist psychology at work", Psychology Review 4. 1998, pp.18-20.

Kohlberg, L. (1968) The child as a moral philosopher: psychology today, in D. Krebs (ed.), Readings in Social Psychology, 2nd edn, London: Harper Collins, 1968

Macionis, Gerber, John, Linda, Sociology, 7th Canadian Ed. Toronto, Ontario: Pearson Canada Inc. , 2010.

Nakdimen KA, The American Joumal of Psychiatry, 1984, 141 (4): pp. 499-503.

OECD. OECD Employment Outlook - 2008 Edition Summary in English. OECD, Paris, 2008, pp. 3-4.

Peter N. Stearns (narrator). A Brief History of the World Course No. 8080 [Audio $\mathrm{CD}$. The Teaching Company.

Sherif, M. "Experiments in group conflict," Scientific American 195, 1956, pp. 54-8.

Shields, S., "Sex and the Biased Scientist," New Scientist 7 December, 1978, pp. 752-4.

Shih, Margaret, Todd L. Pittinsky and Nalini Ambady, "Stereotype Susceptibility: Identity, Salience and Shifts in Quantitative Performance". Psychological Science, 10, 1, 1999, pp. 80-3.

Storr, A., Human Aggression, Harmondsworth: Penguin, 1968.

Tajfel, H., Experiments in intergroup discrimination, Scientific American 223, 1970, pp. 96-102.

Tavris, C., "The mismeasure of woman: paradoxes and perspectives in the study of gender," in J.D. Goodchilds (ed.), Psychological Perspectives on Human Diversity in America, Washington, DC: American Psychological Association, 1991.

The U.S. Equal Employment Opportunity Commission. "Facts About Compensation Discrimination". Retrieved 2008-04-23.

Wagner, David G. and Joseph Berger, Gender and Interpersonal Task Behaviors: Status Expectation Accounts. Sociological Perspectives, 40, 1, 1997, pp.1-32.

Weisstein, N., Psychology constructs the female or the fantasy life of the male psychologist (with some attention to the fantasies of his friends the male biologist and the male anthropologist), in J.S. Bohan (ed.), Seldom Seen, Rarely Heard: Women's Place in Psychology, Boulder, CO: Westview, 1992. 